\title{
Pain Management in Laparoscopic Donor Nephrectomy: A Review
}

\author{
U. Mathuram Thiyagarajan, A. Bagul, and M. L. Nicholson \\ Transplant Surgery Group, Department of Infection, Immunity and Inflammation, Leicester General Hospital, \\ University of Leicester, Gwendolen Road, Leicester LE5 4PW, UK
}

Correspondence should be addressed to U. Mathuram Thiyagarajan, umasurgeon@gmail.com

Received 7 July 2012; Accepted 20 September 2012

Academic Editor: Giustino Varrassi

Copyright () 2012 U. Mathuram Thiyagarajan et al. This is an open access article distributed under the Creative Commons Attribution License, which permits unrestricted use, distribution, and reproduction in any medium, provided the original work is properly cited.

\begin{abstract}
The management of postoperative pain is a key to patient early recovery, in particular, where the surgery was performed to benefit another human being. In recent years it has been recognized that multimodal analgesic methods are superior for postoperative pain relief. It is also imperative to remember that inadequately managed acute postoperative pain opens the doorway to possible suffering from chronic postoperative pain later. Although the laparoscopic donor nephrectomy has reduced the disincentives associated with open surgery, still significant percentage of donors suffers from postoperative pain. In the UK, patient-controlled analgesic system (PCAS) using morphine for postoperative pain relief is being used in majority of the transplant centres. Though opioids provide good analgesia, they are far from being an ideal analgesic due to their adverse effects. This paper pragmatically looks in depth on different modalities of pain management in patients undergoing laparoscopic live donor nephrectomy.
\end{abstract}

\section{Introduction}

The donor nephrectomy is a procedure carried out to benefit another individual and in addition it can add a lot of disincentives to the donor. Subjecting a patient to an open operation leads to increased hospital inpatient stay and a much more painful large scar, thus not only discouraged the potential donors, but also it leads to increased morbidity for long time. This has stimulated the surgeons to come up with an alternative, the laparoscopic donor nephrectomies.

The first laparoscopic live donor nephrectomy (LLDN) was performed by Ratner et al. [1] at the Johns Hopkins Bay view Medical Center, Baltimore, USA in February 1995. The donor was discharged on first postoperative day and returned to work 2 weeks later. This technique thus revolutionized the donor nephrectomy and also removed the added disincentives of open operation.

LLDN is now the preferred method and gold standard operation for kidney donation. Although the LLDN is associated with the longer operation time, it has reduced morphine requirement, hospital stay, and postoperative complications with an early return to work [2]. Randomized controlled trials and systematic reviews confirmed that LLDN is safe and reduce the morbidity following the operation [2-4].

\section{Pain after LLDN}

Pain following the LLDN is multifactorial. Port pain, low abdominal incisions (to retrieve the kidney), pelvic organ nociception, diaphragmatic irritation (shoulder tip discomfort from residual pneumoperitoneum), urinary catheter discomfort add-up and contribute to the total pain experience.

Several studies confirmed that laparoscopic and handassisted nephrectomies produce less pain compared with an open operation [5-9]. Nonetheless, some patients undergoing laparoscopic live donor nephrectomy still suffer significant postoperative pain, to the point where they require parenteral opioids. Based on the assumption that minimally invasive approaches are less traumatic, some units avoid opioids and neuraxial techniques [10].

Nevertheless, LLDN can cause severe neuropathic pain possibly by nerve lesions caused by trocars [11]. The aim of this paper is to create an evidence-based document reviewing 
the current literature with a view to address the best, possible pain relief methods in laparoscopic donor nephrectomy patients.

\section{Postoperative Pain and Its Implications}

Pain has a wide spectrum of effects on the body. Inadequately controlled postoperative pain may have harmful physiologic, psychological consequences which potentially increases the morbidity and mortality $[12,13]$.

It has been recognized that inadequately treated postoperative pain may lead to chronic pain which is often misdiagnosed and neglected $[10,14]$. The significance of this association has been confirmed in other studies on a healthy patients undergoing caesarian section [14] and in patients after inguinal hernia repair [15]. International Association for Study of Pain (IASP) defines the chronic postsurgical pain (CPSP) as pain lasting more than 6 months for nontumour cause and more 3 months in malignancy [16]. Dillenburg et al. [5] found that 20\% patients reported CPSP 6 months after nephrectomy. Similar high incidence of CPSP had been shown after open donor nephrectomy in other studies as well $[17,18]$. In our centre, we have reported $5 \%$ chronic pain in patients undergoing LLDN [19].

The chronic persistent pain after surgery can be caused by many factors but most notably the severity of postoperative pain and psychologic vulnerability. Patients with higher severity of postoperative pain (particularly movement evoked pain-dynamic pain) are more likely to have chronic pain [20-26]. Hence an adequate dynamic pain relief protocol may reduce the development of chronic pain after surgery.

The multimodal analgesic methods have been shown to control this dynamic pain. Opioids are potent analgesics but are mostly inadequate to treat such dynamic pain [27-29], while local anesthetics methods, NSAIDS, $\alpha_{2}$ agonists, and NMDA receptor antagonists may be important for controlling dynamic type of pain and also preventing central sensitization [23-26].

\section{Multimodal Approach}

4.1. NSAIDS. Nonsteroidal anti-inflammatory drugs (NSAIDS) are generally avoided because of their potential nephrotoxicity and other adverse effects. NSAIDS are found to have little effect on surgical stress response and organ dysfunction [30, 31]. But on the other hand, it has been shown that NSAIDS provide moderate postoperative analgesia and thereby an opioid sparing effect in about $20-30 \%$ [18]. Hence they can reduce the incidence of opioids-related adverse effect like nausea, vomiting, respiratory depression, ileus, and bladder disturbances. If NSAIDS are used for less than 5 days with adequate hydration, they can make a potential alternate to opioids.

Freedland et al. [32] used Ketorolac in LLDN patients and noted no differences in renal function. Patients who underwent surgery after introduction of Ketorolac-based analgesia had a significantly shorter postoperative stay. But Ketorolac has been associated with serious side effects including gastrointestinal bleeding, postsurgical bleeding, and impairment of renal function, particularly when used for more than 5 days [33-35]. This hesitates transplant units to widely use the NSAIDS in donor nephrectomy patients.

4.2. Opioids Analgesia. The use of morphine in the postoperative period is a standard practice. Morphine can be given either as an intramuscular/intravenous bolus or through a patient-controlled analgesia system (PCAS). Although PCAS system is widely used, we do not know the best way of morphine administration. Some studies found PCAS as preferred [36, 37], but others could not replicate similar results $[38,39]$. The patient satisfaction is found to be more with the use of PCAS [40] with less nursing time [41]. Recent literature review found that patients getting intramuscular morphine were associated with the higher rate of inadequate analgesia exposure/experience [42].

PCAS does not appear to provide optimal dynamic pain relief after a major surgery [42] Meta-analysis [40] and randomised control trials [41, 43-46] have also shown that postoperative morbidity is not reduced by PCAS compared to intermittent morphine opioids. These findings are consistent with the lack of effect on PCAS on surgical stress response and organ dysfunction $[30,31]$. In addition, high incidences of postoperative nausea/vomiting (PONV), respiratory depression and sedation are noted in morphine use when compared to epidural analgesia [42].

Hence making the use of opioids far from being the ideal postoperative analgesics of choice following a major surgery like LLDN.

4.3. Epidural Analgesia. Usually this technique is used as a substitute for PCAS in LLDN patients. Epidural opioids and local anaesthetics infiltrations are known to provide more effective dynamic pain relief [47]. But it is worth to note that epidural opioids are less effective on stress response [47]. Continuous epidural administration of local anaesthetic (LA) agents or LA plus opioids has been shown to reduce the postoperative pulmonary morbidity after major abdominal surgery [48]. They can also block the sympathetic responses and may reduce the cardiac morbidity [13]. Epidural analgesia is found to be associated with a lower incidence of PONV, sedation, and postoperative bowel dysfunction when compared with opioids [42].

But epidural analgesia has its own problems like urinary retention and risk of infection at the catheter site. Urinary retention is a common problem, and $23 \%$ of patients undergoing an epidural needed a urinary catheterization. Although it is one of the best modality of analgesia, its efficacy in major abdominal procedures is somewhat small because of the insufficient afferent neural blockade [47].

A retrospective series on a cohort of open donor nephrectomy has showed that thoracic epidural analgesia is better than a lumbar [49]. Though epidural analgesia provides good pain relief, it is associated with a lot of complication including nausea (47\%), vomiting (22\%), hypotension (11\%), lower extremity motor blockade (8\%), pruritus (5.5\%), and somnolence (5\%) [49]. Although epidural 
analgesia provides good pain relief, a thorough literature review cannot confirm a single study in LLDN patients.

4.4. Neuraxial Techniques. Blockade of afferent neural stimulus by local anaesthetic agents is very effective in reducing the classical catabolic responses to the surgery $[42,50,51]$. Thus the unusual increase of cortisol, catecholamines, and glucose concentration can be prevented, insulin resistance reduced, glucose and nitrogen economy improved $[42,50,51]$. The unfavorable changes in the coagulatory-fibrinolytic systems are also modified in favour of less thrombosis formation, while most changes in the immune function and markers of inflammation remain unaltered by a neural block and concomitant hormonal inhibition [42, 50, 51]. It is also worth to note that pain relief by other techniques such as epidural analgesia, systemic opioids, NSAIDS is less effective than a normal block with local anaesthetic [50,51]. Opioids are effective at the transmission stage, whereas pre-emptive local anesthetic and peripheral nerve blockade takes effect by preventing conduction of the nociceptive stimulus as well as preventing central sensitization $[20,52]$.

The subfascial administration of local anesthetic has been shown to be much more effective than subcutaneous injection in reducing the pain [52]. Subfascial administration of bupivacaine $(0.5 \%)$ at the trocar and incision sites not only reduced the pain, but also they shortened the hospital stay in patients undergoing a laparoscopic nephrectomy [50].

4.5. Transversus Abdominis Plane (TAP) Block. Since the arrival of a TAP block technique in 2001 [53], it has been widely used for postoperative pain relief. Previous randomised controlled trials have shown that TAP block can reduce postoperative pain and morphine requirement after abdominal surgery for large bowel resection [54] and caesarean section [55]. The later study is particularly relevant as caesarean section is performed through a suprapubic Pfannenstiel incision, which is similar to the approach used for retrieving kidneys that have been dissected laparoscopically.

The preemptive TAP block can potentially reduce the metabolic responses during surgery and also avoid the central sensitization. The principle behind preemptive TAP blocking is that local anaesthetic is injected into the neurofascial plane where it may act on the afferent sensory nerves of the lower 6 thoracic and upper lumbar nerves as they course through the plane before they pierce the musculature to innervate the abdominal wall. This plane is poorly vascularized, and it has been suggested that the prolonged analgesic effect can be observed in TAP blocking, due to slow drug clearance $[54,55]$.

4.5.1. TAP Block Technique. With the patient in the supine position, a 22 gauge $50 \mathrm{~mm}$ blunted regional anesthesia needle was introduced laterally and posterior to the midaxillary line between the iliac crest and the inferior extent of the rib cage. The ultrasound probe is placed in transverse to the long axis of the abdomen and the needle is introduced perpendicular to the linear array beam of ultrasound.

The presence of fascial extensions of the abdominal wall muscles was also used to correctly place the needle tip using the loss of resistance technique. The needle was held perpendicular to the coronal plane and advanced until resistance was encountered and a first "pop" sensation was felt. This indicated that the needle entered the plane between the external and internal oblique layers. The needle was then further advanced until a second "pop" sensation was encountered, indicating that the needle tip had traversed the fascial extensions of the internal oblique and was thus within the transversus abdominis plane.

To date this technique has not been incorporated in to laparoscopic donor nephrectomy patients; thus warrants and justifies a randomised control study to assess its efficacy.

\section{Continuous Infusion on Local Anesthetic Agents}

As we know that local anesthetic agents can provide a lot of benefits without any systemic adverse effects. Recently Biglarnia et al. [56] showed the benefit of continuous infusion of Ropivacaine $(0.5 \%)$ as a tool for postoperative pain relief. But here the donor nephrectomy was done through a hand-assisted retroperitoneoscopic technique (HARS). Two catheters were placed, one in the retroperitoneal space and another in the rectus sheath followed by continuous infusion of ropivacaine into both these spaces. This technique has dramatically reduced pain scoring and cumulative consumption of morphine equivalent.

Panaro et al. [57] have shown that continuous infusion of ropivacaine is a good pain relief technique for laparoscopic donor nephrectomy patients. In this study, retroperitoneal approach was used during the donor nephrectomy. Two catheters were used; one in between parietal peritoneum and muscle layers; second catheter was placed on subcutaneous tissue. This study also showed reduction in the pain score, morphine consumption, and hospital stay compared to the counterpart controls.

Unfortunately similar technique has not been used in transperitoneal LLDN patients. The use of similar technique in transperitoneal approach would be difficult; leaving the catheter for long in peritoneal cavity which also carries the risk of introducing infection and migration.

\section{Long-Acting Local Anesthetics Agents}

The long-acting local anesthetic agents do play an important role in postoperative pain relief. The prospect of long-acting local anesthetic agents that last for long is ideal and attractive but still under investigation in clinical trials. But preemptive portsite infiltration can reduce the central sensitization, facilitates recovery by enabling earlier ambulation [58-60], and may reduce the postoperative analgesics requirement. However, it is most effective for superficial procedures and analgesia which lasts for only $6-8 \mathrm{~h}$.

Simple administration of local anesthetic after the cholecystectomy also reduces the right upper quadrant and shoulder pain $[61,62]$. Although preincisional infiltration reduces the postoperative pain after cholecystectomy, [63-65] other investigators reported showed better pain relief when local anesthetic was infiltrated at the end of surgery [66]. Hence 
the local anesthetic infiltration at trocar site is still controversial [67].

The pain from suprapubic Pfannenstiel incision during the LLDN could be relieved by local anesthetic wound infiltration. Recent studi showed that local anesthetic infiltration before and/or after abdominal hysterectomy does not reduce the intensity of postoperative pain and analgesic requirements $[68,69]$. But another randomized study proves benefit preemptive administration lidocaine efficient mode to reduce pain in the first eight hours after hysterectomy [70]. To date no study has been done in LLDN setting to assess the effect of long-acting local anesthetic agents for postoperative pain relief.

\section{Other Methods}

The acetazolamide can decrease the formation of $\mathrm{H}^{+}$ions thereby retard peritoneal acidification which is probably responsible for visceral and referred pain [71]. Harvey et al. [72] have shown that the intravenous use of acetazolamide reduces referred pain following laparoscopic cholecystectomy.

Singh et al. [73] reported the beneficial use of acetazolamide as a part of multimodal analgesic approach in laparoscopic live donor nephrectomy. In this randomised doubleblinded control trial, nasogastric administration of acetazolamide that has been used in combination of bupivacaine $(0.5 \%)$ installation into renal fossa with $(0.25 \%)$ infiltration at ports and retrieval wound was shown to be effective. The patients who received this multimodal therapy experienced less shoulder tip pain, pain scores at $12 \mathrm{hrs,} \mathrm{total} \mathrm{analgesic}$ requirement with less nausea compared to controls. This study though was not powered to detect the drug-related side effects, it is the first documented study to test acetazolamide role in multimodal analgesia. The role of acetazolamide as a part of multimodal analgesia needs to be researched further.

\section{Conclusion}

The journey of finding the ideal method for pain relief in LLDN patients is yet far from being over. But the arrival of new techniques and multimodal approaches appears to be safe and effective on providing postoperative analgesia. The TAP block technique has not been tested in LLDN patients thus warrants a randomised control trial.

\section{References}

[1] L. E. Ratner, L. J. Ciseck, R. G. Moore, F. G. Cigarroa, H. S. Kaufman, and L. R. Kavoussi, "Laparoscopic live donor nephrectomy," Transplantation, vol. 60, no. 9, pp. 1047-1049, 1995.

[2] M. L. Nicholson, M. Kaushik, G. R. R. Lewis et al., "Randomized clinical trial of laparoscopic versus open donor nephrectomy," British Journal of Surgery, vol. 97, no. 1, pp. 21-28, 2010.

[3] F. Greco, M. R. Hoda, A. Alcaraz, A. Bachmann, O. W. Hakenberg, and P. Fornara, "Laparoscopic living-donor nephrectomy: analysis of the existing literature," European Urology, vol. 58, no. 4, pp. 498-509, 2010.

[4] C. H. Wilson, A. Sanni, D. A. Rix, and N. A. Soomro, "Laparoscopic versus open nephrectomy for live kidney donors,"
Cochrane Database of Systematic Reviews, no. 11, article CD006124, 2011.

[5] W. Dillenburg, V. Poulakis, K. Skriapas et al., "Retroperitoneoscopic versus open surgical radical nephrectomy for large renal cell carcinoma in clinical stage cT2 or cT3a: quality of life, pain and reconvalescence," European Urology, vol. 49, no. 2, pp. 314-322, 2006.

[6] A. Bachmann, T. Wolff, O. Giannini et al., "How painful is donor nephrectomy? Retrospective analysis of early pain and pain management in open versus laparoscopic versus retroperitoneoscopic nephrectomy," Transplantation, vol. 81, no. 12, pp. 1735-1738, 2006.

[7] K. T. Perry, S. J. Freedland, J. C. Hu et al., "Quality of life, pain and return to normal activities following laparoscopic donor nephrectomy versus open mini-incision donor nephrectomy," Journal of Urology, vol. 169, no. 6, pp. 2018-2021, 2003.

[8] M. H. Andersen, L. Mathisen, O. Øyen et al., "Postoperative pain and convalescence in living kidney donors-laparoscopic versus open donor nephrectomy: a randomized study," American Journal of Transplantation, vol. 6, no. 6, pp. 1438-1443, 2006.

[9] S. Jackobs, T. Becker, R. Lück et al., "Quality of life following living donor nephrectomy comparing classical flank incision and anterior vertical mini-incision," World Journal of Urology, vol. 23, no. 5, pp. 343-348, 2005.

[10] M. Williams and Q. J. W. Milner, "Postoperative analgesia following renal transplantation-current practice in the UK," Anaesthesia, vol. 58, no. 7, pp. 712-713, 2003.

[11] M. G. Oefelein and Y. Bayazit, "Chronic pain syndrome after laparoscopic radical nephrectomy," Journal of Urology, vol. 170, no. 5, pp. 1939-1940, 2003.

[12] G. P. Joshi, "Multimodal analgesia techniques and postoperative rehabilitation," Anesthesiology Clinics of North America, vol. 23, no. 1, pp. 185-202, 2005.

[13] S. S. Liu, R. L. Carpenter, D. C. Mackey et al., "Effects of perioperative analgesic technique on rate of recovery after colon surgery," Anesthesiology, vol. 83, pp. 757-765, 1995.

[14] L. Nikolajsen, H. C. Sørensen, T. S. Jensen, and H. Kehlet, "Chronic pain following Caesarean section," Acta Anaesthesiologica Scandinavica, vol. 48, no. 1, pp. 111-116, 2004.

[15] M. Bay-Nielsen, F. M. Perkins, and H. Kehlet, "Pain and functional impairment 1 year after inguinal herniorrhaphy: a nationwide questionnaire study," Annals of Surgery, vol. 233, no. 1, pp. 1-7, 2001.

[16] H. Merskey and N. Bogduk, Description of Chronic Pain Syndromes and Definitions of Pain Terms, IASP Press, Seattle, Wash, USA, 1994.

[17] M. Owen, P. Lorgelly, and M. Serpell, "Chronic pain following donor nephrectomy-a study of the incidence, nature and impact of chronic post-nephrectomy pain," European Journal of Pain, vol. 14, no. 7, pp. 732-734, 2010.

[18] S. Chatterjee, R. Nam, N. Fleshner, and L. Klotz, "Permanent flank bulge is a consequence of flank incision for radical nephrectomy in one half of patients," Urologic Oncology, vol. 22, no. 1, pp. 36-39, 2004.

[19] J. R. Waller, A. L. Hiley, E. J. Mullin, P. S. Veitch, and M. L. Nicholson, "Living kidney donation: a comparison of laparoscopic and conventional open operations," Postgraduate Medical Journal, vol. 78, no. 917, pp. 153-157, 2002.

[20] J. Katz, M. Jackson, B. P. Kavanagh, and A. N. Sandler, "Acute pain after thoracic surgery predicts long-term post-thoracotomy pain," Clinical Journal of Pain, vol. 12, no. 1, pp. 50-55, 1996. 
[21] T. Tasmuth, M. Kataja, C. Blomqvist, K. Von Smitten, and E. Kalso, "Treatment-related factors predisposing to chronic pain in patients with breast cancer: a multivariate approach," Acta Oncologica, vol. 36, no. 6, pp. 625-630, 1997.

[22] T. Callesen, K. Bech, and H. Kehlet, "Prospective study of chronic pain after groin hernia repair," British Journal of Surgery, vol. 86, no. 12, pp. 1528-1531, 1999.

[23] E. Aasvang and H. Kehlet, "Chronic postoperative pain: the case of inguinal herniorrhaphy," British Journal of Anaesthesia, vol. 95, no. 1, pp. 69-76, 2005.

[24] T. Bisgaard, B. Klarskov, J. Rosenberg, and H. Kehlet, "Characteristics and prediction of early pain after laparoscopic cholecystectomy," Pain, vol. 90, no. 3, pp. 261-269, 2001.

[25] E. L. Poleshuck, J. Katz, C. H. Andrus et al., "Risk factors for chronic pain following breast cancer surgery: a prospective study," Journal of Pain, vol. 7, no. 9, pp. 626-634, 2006.

[26] H. J. Gerbershagen, O. Dagtekin, T. Rothe et al., "Risk factors for acute and chronic postoperative pain in patients with benign and malignant renal disease after nephrectomy," European Journal of Pain, vol. 13, no. 8, pp. 853-860, 2009.

[27] H. Kehlet, "Postoperative pain relief-what is the issue?" British Journal of Anaesthesia, vol. 72, no. 4, pp. 375-378, 1994.

[28] M. Tverskoy, M. Oren, I. Dashkovsky, and I. Kissin, "Alfentanil dose-response relationships for relief of postoperative pain," Anesthesia and Analgesia, vol. 83, no. 2, pp. 387-393, 1996.

[29] C. H. Wilder-Smith, L. Hill, J. Wilkins, and L. Denny, "Effects of morphine and tramadol on somatic and visceral sensory function and gastrointestinal motility after abdominal surgery," Anesthesiology, vol. 91, no. 3, pp. 639-647, 1999.

[30] H. Kehlet, "Multimodal approach to control postoperative pathophysiology and rehabilitation," British Journal of Anaesthesia, vol. 78, no. 5, pp. 606-617, 1997.

[31] H. Kehlet, "Modification of responses to surgery by neural blockade: clinical implications," in Neural Blockade in Clinical Aneathesia and Management of Pain, M. J. Cousins and Bridenbaugh, Eds., pp. 129-171, Lippincott-Raven, Philadelphia, Pa, USA, 3rd edition, 1998.

[32] S. J. Freedland, M. Blanco-Yarosh, J. C. Sun et al., "Ketorolacbased analgesia improves outcomes for living kidney donors," Transplantation, vol. 73, no. 5, pp. 741-745, 2002.

[33] J. C. Gillis and R. N. Brogden, "Ketorolac: a reappraial of its pharmacodynamic and pharmacokinetic properties and therapeutic use in pain management," Drugs, vol. 53, no. 1, pp. 139-188, 1997.

[34] H. I. Feldman, J. L. Kinman, J. A. Berlin et al., "Parenteral ketorolac: the risk for acute renal failure," Annals of Internal Medicine, vol. 126, no. 3, pp. 193-199, 1997.

[35] B. L. Strom, J. A. Berlin, J. L. Kinman et al., "Parenteral ketorolac and risk of gastrointestinal and operative site bleeding: a postmarketing surveillance study," Journal of the American Medical Association, vol. 275, no. 5, pp. 376-382, 1996.

[36] A. M. Chang, W. Y. Ip, and T. H. Cheung, "Patient-controlled analgesia versus conventional intramuscular injection: a cost effectiveness analysis," Journal of Advanced Nursing, vol. 46, no. 5, pp. 531-541, 2004.

[37] M. P. Lange, M. S. Dahn, and L. A. Jacobs, "Patient-controlled analgesia versus intermittent analgesia dosing," Heart and Lung, vol. 17, no. 5, pp. 495-498, 1988.

[38] D. M. Rosen, A. M. Lam, M. A. Carlton, G. M. Cario, and L. McBride, "Analgesia following major gynecological laparoscopic surgery-PCA versus intermittent intramuscular injection," Journal of the Society of Laparoendoscopic Surgeons, vol. 2, no. 1, pp. 25-29, 1998.
[39] E. Gorevski, S. Wead, A. Tevar, P. Succop, P. Volek, and J. Martin-Boone, "Retrospective evaluation of donor pain and pain management after laprascopic nephrectomy," Transplantation Proceedings, vol. 43, no. 7, pp. 2487-2491, 2011.

[40] J. C. Ballantyne, D. B. Carr, T. C. Chalmers, K. B. G. Dear, I. F. Angelillo, and F. Mosteller, "Postoperative patient-controlled analgesia: meta-analyses of initial randomized control trials," Journal of Clinical Anesthesia, vol. 5, no. 3, pp. 182-193, 1993.

[41] A. Boulanger, M. Choiniere, D. Roy et al., "Comparison between patient-controlled analgesia and intramuscular meperidine after thoracotomy," Canadian Journal of Anaesthesia, vol. 40, no. 5 I, pp. 409-415, 1993.

[42] S. J. Dolin, J. N. Cashman, and J. M. Bland, "Effectiveness of acute postoperative pain management: I. Evidence from published data," British Journal of Anaesthesia, vol. 89, no. 3, pp. 409-423, 2002.

[43] V. W. S. Chan, F. Chung, M. McQuestion, and M. Gomez, "Impact of patient-controlled analgesia on required nursing time and duration of postoperative recovery," Regional Anesthesia, vol. 20, no. 6, pp. 506-514, 1995.

[44] C. W. Colwell Jr. and B. A. Morris, "Patient-controlled analgesia compared with intramuscular injection of analgesics for the management of pain after an orthopaedic procedure," Journal of Bone and Joint Surgery A, vol. 77, no. 5, pp. 726-733, 1995.

[45] A. M. Egbert, L. H. Parks, L. M. Short, and M. L. Burnett, "Randomized trial of postoperative patient-controlled analgesia vs intramuscular narcotics in frail elderly men," Archives of Internal Medicine, vol. 150, no. 9, pp. 1897-1903, 1990.

[46] R. Gust, S. Pecher, A. Gust, V. Hoffmann, H. Böhrer, and E. Martin, "Effect of patient-controlled analgesia on pulmonary complications after coronary artery bypass grafting," Critical Care Medicine, vol. 27, no. 10, pp. 2218-2223, 1999.

[47] H. Kehlet and K. Holte, "Effect of postoperative analgesia on surgical outcome," British Journal of Anaesthesia, vol. 87, no. 1, pp. 62-72, 2001.

[48] N. V. Addison, F. A. Brear, K. Budd, and M. Whittaker, "Epidural analgesia following cholecystectomy," British Journal of Surgery, vol. 61, no. 10, pp. 850-852, 1974.

[49] L. Suarez-Sanchez, E. Perales-Caldera, M. C. Pelaez-Luna, and R. Bernal-Flores, "Postoperative outcome of open donor nephrectomy under epidural analgesia: a descriptive analysis," Transplantation Proceedings, vol. 38, no. 3, pp. 877-881, 2006.

[50] E. E. Ashcraft, G. M. Baillie, S. F. Shafizadeh et al., "Further improvements in laparoscopic donor nephrectomy: decreased pain and accelerated recovery," Clinical Transplantation, vol. 15, no. 6, pp. 59-61, 2001.

[51] H. Kehlet, "General versus regional anaesthesia," in Principles and Practice of Anesthesiology, M. Rogers, J. Tinker, B. Covino, and D. E. Longnecker, Eds., pp. 1218-1234, Mosby, St. Louis, Mo, USA, 1993.

[52] S. Yndgaard, P. Holst, K. Bjerre-Jepsen, C. B. Thomsen, J. Struckmann, and T. Mogensen, "Subcutaneously versus subfascially administered lidocaine in pain treatment after inguinal herniotomy," Anesthesia and Analgesia, vol. 79, no. 2, pp. 324-327, 1994.

[53] A. N. Rafi, "Abdominal field block: a new approach via the lumbar triangle," Anaesthesia, vol. 56, no. 10, pp. 1024-1026, 2001.

[54] J. G. McDonnell, B. O’Donnell, G. Curley, A. Heffernan, C. Power, and J. G. Laffey, "The analgesic efficacy of transversus abdominis plane block after abdominal surgery: a prospective randomized controlled trial," Anesthesia and Analgesia, vol. 104, no. 1, pp. 193-197, 2007. 
[55] J. G. McDonnell, G. Curley, J. Carney et al., "The analgesic efficacy of transversus abdominis plane block after cesarean delivery: a randomized controlled trial," Anesthesia and Analgesia, vol. 106, no. 1, pp. 186-191, 2008.

[56] A. R. Biglarnia, G. Tufveson, T. Lorant, F. Lennmyr, and J. Wadström, "Efficacy and safety of continuous local infusion of ropivacaine after retroperitoneoscopic live donor nephrectomy," American Journal of Transplantation, vol. 11, no. 1, pp. 93-100, 2011.

[57] F. Panaro, F. Gheza, T. Piardi et al., "Continuous infusion of local anesthesia after living donor nephrectomy: a comparative analysis," Transplantation Proceedings, vol. 43, no. 4, pp. 985987, 2011.

[58] J. D. Vloka, A. Hadžić, R. Mulcare, J. B. Lesser, E. Kitain, and D. M. Thys, "Femoral and genitofemoral nerve blocks versus spinal anesthesia for outpatients undergoing long saphenous vein stripping surgery," Anesthesia and Analgesia, vol. 84, no. 4, pp. 749-752, 1997.

[59] S. Li, M. Coloma, P. F. White et al., "Comparison of the costs and recovery profiles of three anesthetic techniques for ambulatory anorectal surgery," Anesthesiology, vol. 93, no. 5, pp. 1225-1230, 2000.

[60] D. Song, N. B. Greilich, P. F. White, M. F. Watcha, and W. K. Tongier, "Recovery profiles and costs of anesthesia for outpatient unilateral inguinal herniorrhaphy," Anesthesia and Analgesia, vol. 91, no. 4, pp. 876-881, 2000.

[61] C. Michaloliakou, F. Chung, and S. Sharma, "Preoperative multimodal analgesia facilitates recovery after ambulatory laparoscopic cholecystectomy," Anesthesia and Analgesia, vol. 82, no. 1, pp. 44-51, 1996.

[62] K. I. A. Gharaibeh and T. M. Al-Jaberi, "Bupivacaine instillation into gallbladder bed after laparoscopic cholecystectomy: does it decrease shoulder pain?" Journal of Laparoendoscopic and Advanced Surgical Techniques A, vol. 10, no. 3, pp. 137$141,2000$.

[63] T. Bisgaard, B. Klarskov, V. B. Kristiansen et al., "Multiregional local anesthetic infiltration during laparoscopic cholecystectomy in patients receiving prophylactic multi-modal analgesia: a randomized, double-blinded, placebo-controlled study," Anesthesia and Analgesia, vol. 89, no. 4, pp. 1017-1024, 1999.

[64] S. Y. Fong, T. J. Pavy, S. T. Yeo, M. J. Paech, and L. C. Gurrin, "Assessment of wound infiltration with bupivacaine in women undergoing day-case gynecological laparoscopy," Regional Anesthesia and Pain Medicine, vol. 26, no. 2, pp. 131-136, 2001.

[65] N. W. Hasaniya, F. F. Zayed, H. Faiz, and R. Severino, "Preinsertion local anesthesia at the trocar site improves perioperative pain and decreases costs of laparoscopic cholecystectomy," Surgical Endoscopy, vol. 15, no. 9, pp. 962-964, 2001.

[66] A. M. Sarac, A. O. Aktan, N. Baykan, C. Yegen, and R. Yalin, "The effect and timing of local anesthesia in laparoscopic cholecystectomy," Surgical Laparoscopy, Endoscopy and Percutaneous Techniques, vol. 6, no. 5, pp. 362-366, 1996.

[67] S. Møiniche, H. Jørgensen, J. Wetterslev, and J. B. Dahl, "Local anesthetic infiltration for postoperative pain relief after laparoscopy: a qualitative and quantitative systematic review of intraperitoneal, port-site infiltration and mesosalpinx block," Anesthesia and Analgesia, vol. 90, no. 4, pp. 899-912, 2000.

[68] S. Hariharan, H. Moseley, A. Kumar, and S. Raju, "The effect of preemptive analgesia in postoperative pain relief - a prospective double-blind randomized study," Pain Medicine, vol. 10, no. 1, pp. 49-53, 2009.

[69] J. R. Klein, J. P. Heaton, J. P. Thompson, B. R. Cotton, A. C. Davidson, and G. Smith, "Infiltration of the abdominal wall with local anaesthetic after total abdominal hysterectomy has no opioid-sparing effect," British Journal of Anaesthesia, vol. 84, no. 2, pp. 248-249, 2000.

[70] L. Lowenstein, E. Z. Zimmer, M. Deutsch, Y. Paz, D. Yaniv, and P. Jakobi, "Preoperative analgesia with local lidocaine infiltration for abdominal hysterectomy pain management," European Journal of Obstetrics Gynecology and Reproductive Biology, vol. 136, no. 2, pp. 239-242, 2008.

[71] H. I. E. Ives, "Diuretic Agents," in Basic and Clinical Pharmacology, B. G. Katzung, Ed., pp. 241-258, Lange, New York, NY, USA, 9th edition, 2004.

[72] J. W. Harvey, M. Otterson, H. Yun, L. A. Connolly, D. Eastwood, and K. Colpaert, "Acetazolamide reduces referred postoperative pain after laparoscopic surgery with carbon dioxide insufflation," Anesthesiology, vol. 99, no. 4, pp. 924-928, 2003.

[73] R. Singh, I. Sen, J. Wig, M. Minz, A. Sharma, and I. Bala, “An acetazolamide based multimodal analgesic approach versus conventional pain management in patients undergoing laparoscopic living donor nephrectomy," Indian Journal of Anaesthesia, vol. 53, no. 4, pp. 434-441, 2009. 


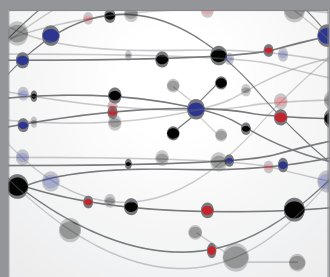

The Scientific World Journal
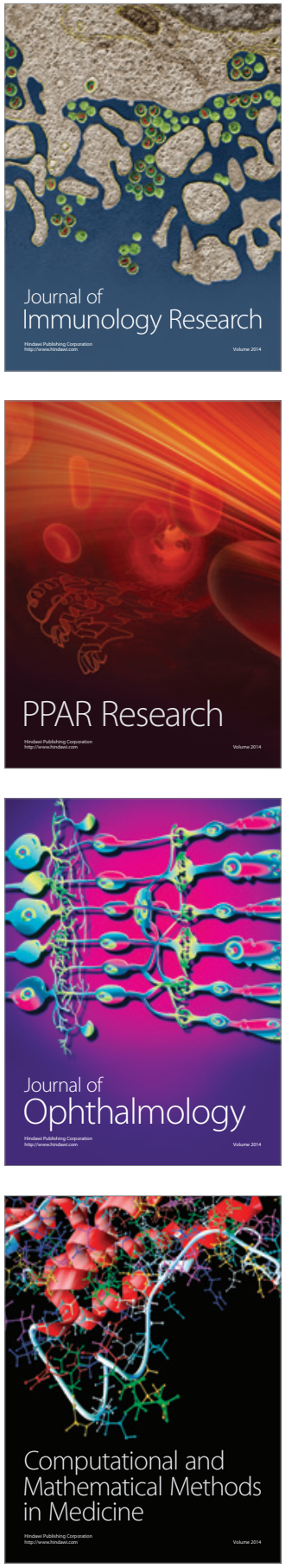

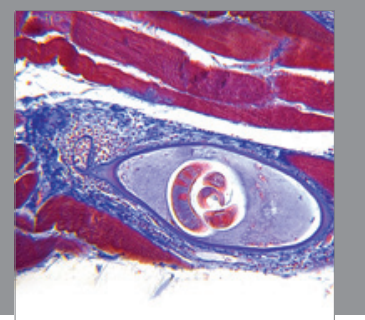

Gastroenterology

Research and Practice
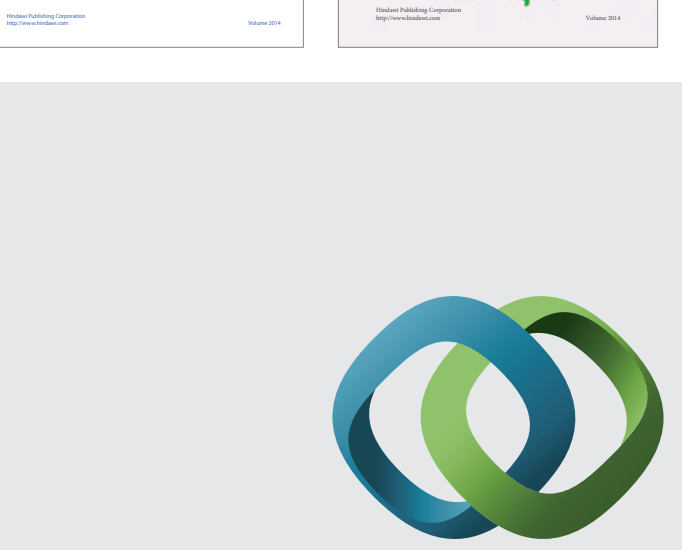

\section{Hindawi}

Submit your manuscripts at

http://www.hindawi.com
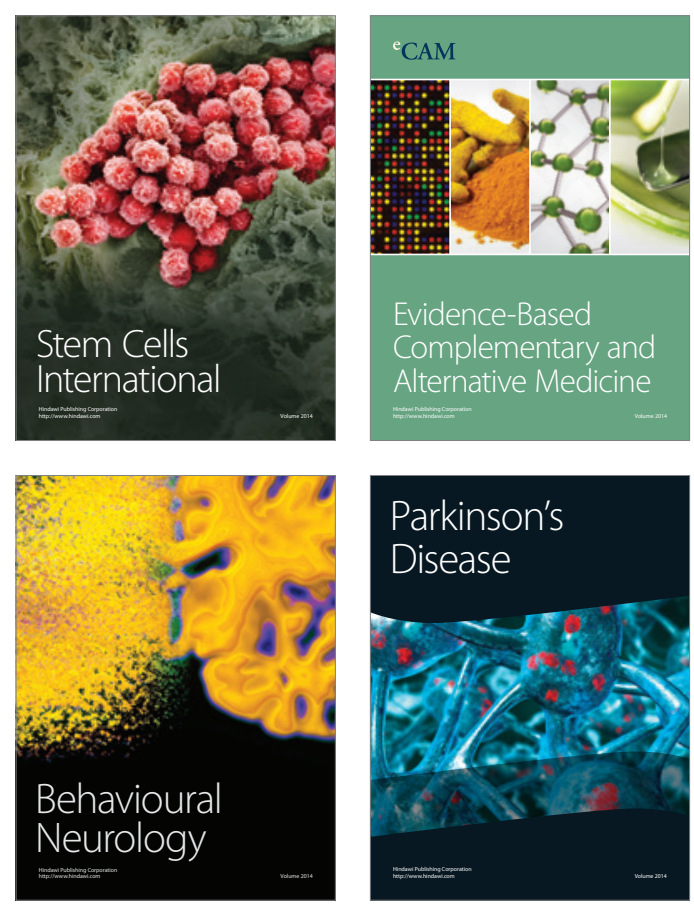

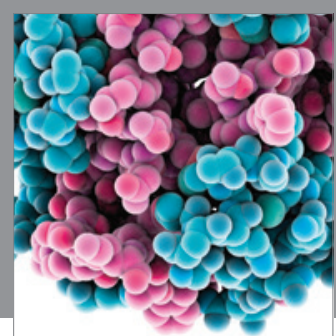

Journal of
Diabetes Research

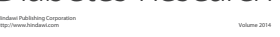

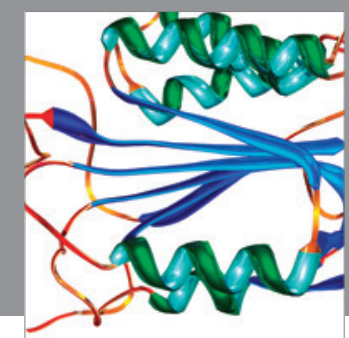

Disease Markers
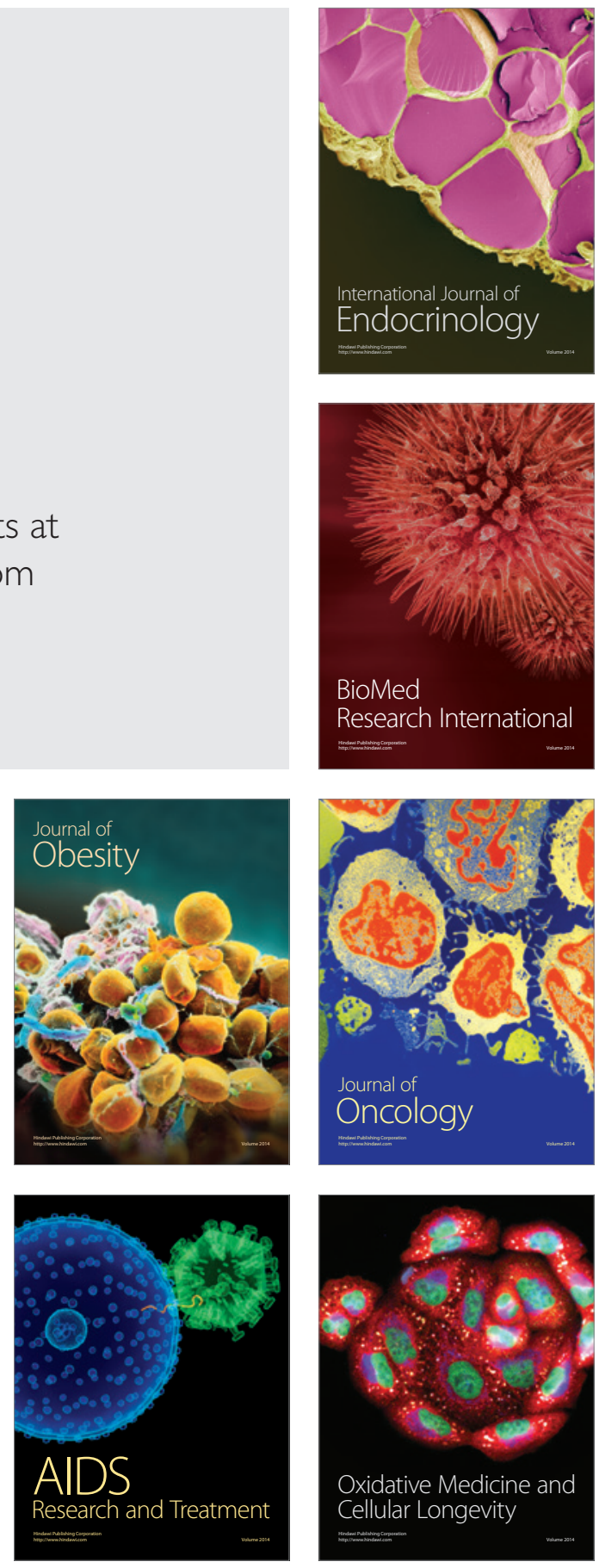